\title{
Transposition: The knowns and the unknowns
}

\author{
Bassem N. Mora, MD, and Joseph A. Dearani, MD,
}

\author{
From the Division of Cardiovascular Surgery, Mayo Clinic, Rochester, Minn. \\ Disclosures: Authors have nothing to disclose with regard to commercial support. \\ Received for publication Oct 12, 2015; accepted for publication Oct 13, 2015. \\ Address for reprints: Bassem N. Mora, MD, Division of Cardiovascular Surgery, Mayo Clinic, 200 First St SW, \\ Rochester, MN 55905 (E-mail: mora.bassem@mayo.edu). \\ J Thorac Cardiovasc Surg 2016;151:15-7 \\ $0022-5223 / \$ 36.00$ \\ Copyright (c) 2016 by The American Association for Thoracic Surgery \\ http://dx.doi.org/10.1016/j.jtcvs.2015.10.035
}

Transposition of the great arteries (TGA) is the most common cyanotic heart anomaly seen in the neonatal period; without intervention, most patients do not survive. The Senning and Mustard atrial switch procedures were devised to reroute atrial blood, preserving the ventricular outflow tracts with their respective arterial connections, leaving the right ventricle (RV) to support the systemic circulation. During the 1950s, several surgeons attempted aspects of the arterial switch operation (ASO), with uniformly fatal results, until Jatene perfected the technique of coronary transfer. Subsequently, Norwood and Castaneda performed the first successful neonatal ASO, heralding the modern treatment of dextro-TGA (D-TGA). ${ }^{1}$ There was much debate at the time, questioning the wisdom of performing a neonatal ASO in an otherwise stable patient who was amenable to a lower-risk atrial switch procedure later in infancy. It was not until the cohort of patients entering the 2 pathways was studied, with the now known increased mortality of the atrial switch cohort before surgical intervention, that the neonatal ASO became the standard of care.

There are many adult patients who underwent atrial switch procedures in infancy. Late complications of systemic or pulmonary venous pathway obstruction, systemic atrioventricular valve regurgitation, systemic RV dysfunction, and rhythm disturbances are well documented, and management guidelines have been developed. ${ }^{2}$ The fate of the systemic RV remains an area of investigation. It is clear that not all systemic RVs are the same. Some systemic RVs fail early, whereas others do not. Significant tricuspid regurgitation develops in some patients, but not in others. Conventional tricuspid valve surgery may be feasible for some patients, whereas others require a transplant. Internal cardioverter-defibrillator implantation is often necessary when severe RV dysfunction is present, whereas other patients undergo cardiac resynchronization therapy. The article in this issue of the Journal from the Boston group helps address some of these questions. ${ }^{3}$ In addition, some patients are women of childbearing age. Recommendations regarding the feasibility of pregnancy and subsequent development of heart failure and systemic RV dysfunction are quite variable. Although the literature indicates worse

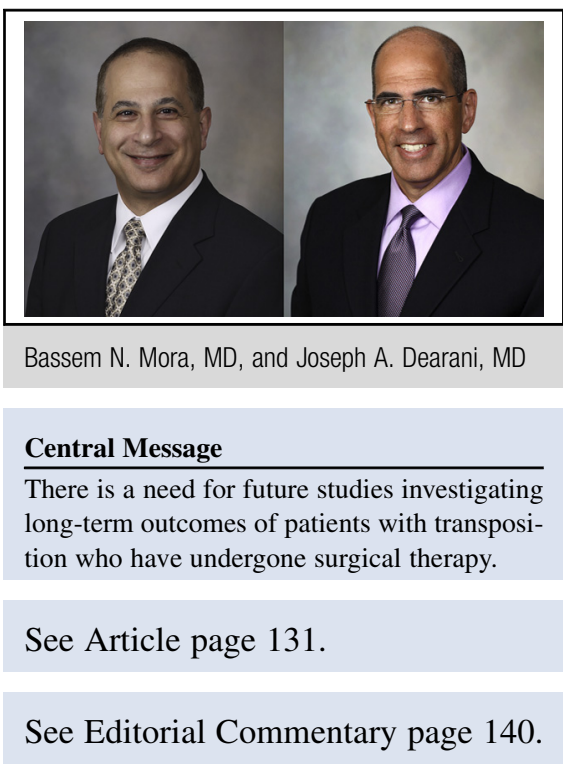

outcome with retraining of the left ventricle (LV) in the older population, there may still be a role for it in selected circumstances in the teenager and young adult. In the developing world, some patients with D-TGA are seen late. Although in the current era the atrial switch is rarely applied for D-TGA, there is a role for the atrial switch in these patients with late presentation, particularly when limited resources prevent LV retraining for a subsequent ASO.

The atrial switch operation is also part of the "doubleswitch" operation for congenitally corrected TGA. Most surgeons favor the Senning atrial switch as part of the double-switch procedure, citing decreased venous baffle obstruction and improved survival. The article in this issue of the Journal from the Dallas group addresses some of these issues. ${ }^{4}$ There remains a role for the Mustard procedure, especially in patients with dextrocardia. The hemiMustard (baffling the inferior vena cava to the tricuspid valve while adding a bidirectional cavopulmonary shunt) has a role in RV hypoplasia or dysfunction, although some have advocated more widespread use. ${ }^{5}$ Should the double-switch procedure be performed in patients with complex coronary anomalies, such as inverted, single, or intramural coronaries? What is the role of even more complex procedures, such as double root translocation, ${ }^{6}$ pulmonary root translocation, ${ }^{7}$ or en bloc rotation of the truncus arteriosus $?^{8}$ Still so many questions to answer.

Numerous studies have investigated early and late outcomes after the ASO. A study from Columbia University concluded that the ASO should be performed on the third day of life. ${ }^{9}$ Fetal echocardiography allows prenatal 
diagnosis for most patients with D-TGA. Should an ASO on the third day of life become the new standard-of-care? Although preoperative echocardiography at the time of the ASO often documents coronary artery anatomy, some patients are diagnosed intraoperatively with coronary artery anomalies. Although most coronary artery anomalies are no longer considered a risk factor for early mortality after the ASO, some rare lesions still pose a significant risk, such as intramural coronaries. Potential late complications after the ASO include coronary artery stenosis or occlusion. Current adult congenital heart disease guidelines recommend documentation of coronary artery patency. Most coronary artery stenoses are ostial, resulting from torsion, kinking, or adventitial injury at the time of the ASO. The role of coronary artery bypass grafting versus coronary ostial patch angioplasty remains to be determined. Furthermore, some older patients with coronary abnormalities who underwent neonatal ASO often have no symptoms and no evidence of ischemia, and recommendations for intervention can be challenging for these patients.

The most common postoperative complication after the ASO is supravalvular pulmonary stenosis (PS). Various surgical techniques have been advocated, such as pantaloon pericardial patches and extensive pulmonary artery mobilization to decrease anastomotic tension. Although these techniques have decreased the risk of supravalvular PS, the incidence is not negligible. The fate of the neoaortic valve and root also deserve comment. Various studies have documented dilatation of the neoaortic root, although the exact threshold for reintervention is unclear. Although aortic dilatation in conotruncal anomalies is common, the risks of dissection and rupture are low. Although guidelines for intervention in this population with congenital heart disease need to be developed, what do clinicians do in the interim to guide treatment, follow guidelines for adult aortopathies? Most patients will have mild or trivial neoaortic regurgitation in the setting of a dilated aortic root, and some will have significant regurgitation. What are the modifiable surgical factors that can decrease neoaortic regurgitation at the time of the ASO? The literature documents excellent late survival after the ASO, and data regarding functional ability, health status, and qualify-of-life are growing.

Patients with complex TGA deserve special mention; for example, the Taussig-Bing heart, with side-by-side great vessels, arch hypoplasia, and coronary anomalies. The presence of a subpulmonary ventricular septal defect allows baffling of the LV to the native pulmonary valve followed by an ASO. Should the subpulmonary conus be routinely excised to prevent the future development of LV outflow tract obstruction? Patients with TGA, ventricular septal defect, and PS also present a management dilemma. The Rastelli procedure has been the treatment of choice. Should the conal septum be routinely resected to prevent LV outflow tract obstruction? Does the need for multiple RV-pulmonary artery conduit replacements after the Rastelli procedure favor the réparation à l'etage ventriculaire (REV) procedure with obligate pulmonary regurgitation? The enthusiasm for the Nikaidoh procedure for TGA, ventricular septal defect, and PS is growing, and many technical questions have come up. Should the Nikaidoh be performed on the beating heart? ${ }^{10}$ Should the coronary buttons be left attached, or should they be reimplanted into the translocated root? Should the aortic root be rotated $180^{\circ} ?^{11}$ Does the added surgical morbidity and mortality of the Nikaidoh procedure justify its use instead of the Rastelli procedure where the coronary arteries are not disturbed? The article in this issue of the Journal from the Toronto group addresses some of these questions. $^{12}$

There have been many lessons learned during the past 50 years about outcomes after the atrial switch procedure and the ASO. Although early mortality is low for both operations, some patients do have late complications. Improved imaging and evolving medical and surgical therapies are being applied to help mitigate these late problems. There are many unanswered questions that affect late survival and quality of life. The use of national databases and registries will provide a more thorough understanding of these early and late problems and facilitate improved evidence-based management guidelines in the future.

\section{References}

1. Castaneda AR, Norwood WI, Jonas RA, Colan SD, Sanders SP, Lang P. Transposition of the great arteries and intact ventricular septum: anatomical repair in the neonate. Ann Thorac Surg. 1984;38:438-43.

2. Warnes C, Williams RG, Bashore TM, Child JS, Connolly HM, Dearani JA, et al. ACC/AHA 2008 guidelines for the management of adults with congenital heart disease: disease: a report of the American College of Cardiology/American Heart Association Task Force on Practice Guidelines (Writing Committee to Develop Guidelines for the Management of Adults With Congenital Heart Disease). Circulation. 2008;118:e714-833.

3. Hofferberth SC, Alexander ME, Mah DY, Bautista-Hernandez V, Del Nido PJ, FynnThompson F. Impact of pacing on systemic ventricular function in 1-transposition of the great arteries. J Thorac Cardiovasc Surg. 2016;151:131-9.

4. Ferro G, Murthy R, Sebastian V, Guleserian KJ, Forbess JM. Single center experience with the Senning procedure in the current era. J Thorac Cardiovasc Surg. 2015 [Submitted].

5. Malhotra SP, Reddy VM, Qiu M, Pirolli TJ, Barboza L, Reinhartz O, et al. The hemi-Mustard/bidirectional Glenn atrial switch procedure in the double-switch operation for congenitally corrected transposition of the great arteries: rationale and midterm results. J Thorac Cardiovasc Surg. 2011;141:162-70.

6. Hu S, Xie Y, Li S, Wang X, Yan F, Li Y, et al. Double-root translocation for double-outlet right ventricle with noncommitted ventricular septal defect or double-outlet right ventricle with subpulmonary ventricular septal defect associated with pulmonary stenosis: an optimized solution. Ann Thorac Surg. 2010;89: 1360-5.

7. Da Silva JP, Baumgratz JF, da Fonseca L. Pulmonary root translocation in transposition of great arteries repair. Ann Thorac Surg. 2000;60:643-5.

8. Mair R, Sames-Dolzer E, Vondrys D, Lechner E, Tulzer G. En bloc rotation of the truncus arteriosus - an option for anatomic repair of transposition of the great arteries, ventricular septal defect, and left ventricular outflow tract obstruction. $J$ Thorac Cardiovasc Surg. 2006;131:740-1. 
9. Anderson BR, Ciarleglio AJ, Hayes DA, Quaegebeur JM, Vincent JA, Bacha EA. Earlier arterial switch operation improves outcomes and reduces costs for neonates with transposition of the great arteries. J Am Coll Cardiol. 2014;63:481-7.

10. Bautista-Hernandez V, Nento DE, Colan SD, Geva T, Pigula FA. Aortic translocation for the management of double-outlet right ventricle and pulmonary stenosis with dextrocardia: technique to avoid coronary insufficiency. Ann Thorac Surg. 2010;89:633-5.
11. Bautista-Hernandez V, Marx G, Bacha EA, Del Nido PJ. Aortic root translocation plus arterial switch for transposition of the great arteries with left ventricular outflow tract obstruction: intermediate-term results. J Am Coll Cardiol. 2007; 49:485-90.

12. Al-Jughiman M, Al-Omair M, Mertens L, Caldarone CA, Van Arsdell G. What is the procedure impact on ventricular outflow tract hemodynamics and reintervention in patients with complex transposition? J Thorac Cardiovasc Surg. 2015 [Submitted]. 